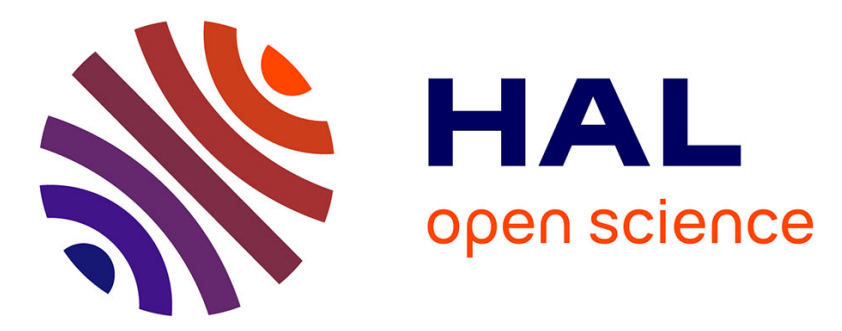

\title{
Optimisation of extrusion flat die design and die wall temperature distribution, using Kriging and response surface method
}

\author{
Nadhir Lebaal, Fabrice Schmidt, Stephan Puissant
}

\section{To cite this version:}

Nadhir Lebaal, Fabrice Schmidt, Stephan Puissant. Optimisation of extrusion flat die design and die wall temperature distribution, using Kriging and response surface method. International Journal of Materials and Product Technology, 2010, 38 (2-3), pp.307-322. 10.1504/IJMPT.2010.032107 . hal01716277

\section{HAL Id: hal-01716277 \\ https://hal.science/hal-01716277}

Submitted on 19 Mar 2019

HAL is a multi-disciplinary open access archive for the deposit and dissemination of scientific research documents, whether they are published or not. The documents may come from teaching and research institutions in France or abroad, or from public or private research centers.
L'archive ouverte pluridisciplinaire HAL, est destinée au dépôt et à la diffusion de documents scientifiques de niveau recherche, publiés ou non, émanant des établissements d'enseignement et de recherche français ou étrangers, des laboratoires publics ou privés. 


\title{
Optimisation of extrusion flat die design and die wall temperature distribution, using Kriging and response surface method
}

\author{
Nadhir Lebaal* \\ Institut Supérieur d'Ingénierie de la Conception (GIP-InSIC), \\ Equipe de Recherche en Mécanique et Plasturgie "ERMeP", \\ 27 rue d'Hellieule, \\ 88100 Saint-Dié-des-Vosges, France \\ E-mail: nadhir.lebaal@insic.fr \\ Website: http://www.insic.fr \\ ${ }^{*}$ Corresponding author
}

\section{Fabrice Schmidt}

Ecole des mines d'Albi Carmaux (ENSTIMAC),

Centre de Recherche Outillages,

Matériaux et Procédés "CROMeP",

Campus Jarlard- Route de Teillet 81013 Albi Cedex 9, France

E-mail: fabrice.schmidt@enstimac.fr

\section{Stephan Puissant}

Institut Supérieur d'Ingénierie de la Conception (GIP-InSIC),

Equipe de Recherche en Mécanique et Plasturgie "ERMeP",

27 rue d'Hellieule,

88100 Saint-Dié-des-Vosges, France

E-mail: stephan.puissant@insic.fr

\begin{abstract}
A new optimisation methodology for the design of coat-hanger dies is presented. Two approaches are presented to optimise the velocities distribution across the die exit. In the first approach, we predict the optimal shape of a coat hanger die; in the second approach, to keep the same geometry and avoid design of a new die, we optimise the temperature of regulation in heterogeneous way. This method involves coupling a three-dimensional finite element simulation software and an optimisation strategy. For this optimisation, the Sequential Quadratic Programming algorithm and the global response surface method with Kriging interpolation are used.
\end{abstract}

Keywords: polymer extrusion; thermal regulation; response surface method; optimisation; Kriging interpolation; finite element analysis.

Reference to this paper should be made as follows: Lebaal, N., Schmidt, F. and Puissant, S. (2010) 'Optimisation of extrusion flat die design and die wall temperature distribution, using Kriging and response surface method', Int. J. Materials and Product Technology, Vol. 38, Nos. 2/3, pp.307-322. 
Biographical notes: N. Lebaal received his $\mathrm{PhD}$ in Mechanics and Energy from Institut National Polytechnique de Lorraine (INPL) France. He is currently an Associate Professor at Ecole des Mines of Albi- Carmaux, attached in the superior institute of engineering and Design (GIP-InSIC) in Saint Dié des Vosges-France. His research interests include: material processing and design, polymer extrusion, finite element method, optimisation, intelligence die design.

F. Schmidt has defended his $\mathrm{PhD}$ in Materials Science and Engineering, CEMEF (ENSMP) in 1995. He is actually Professor at EMAC (Ecole des Mines Albi-Carmaux, France) and research group manager of "Composite Materials and Structures". His research activities are focused on polymers processing (infrared heating modelling using ray tracing method for stretch blow moulding and thermoforming processes; thermal optimisation of injection moulds, liquid resin infusion simulation, ...). $\mathrm{He}$ is author or co-author of around 80 papers including conference papers.

S. Puissant has defended his $\mathrm{PhD}$ in Materials Science and Engineering, CEMEF (ENSMP) in 1992. He is actually on leave from EMAC and technology manager of the BU CTP (Coated Transmission Products) in Brugg Cables in Switzerland. His research and development activities are focused on polymers processing and more particularly on extrusion.

\section{Introduction}

Extrusion defects such as weld-lines, non-uniform exit velocity distribution across the extrusion die and problems of stagnation zones are influenced by the geometry of the extrusion die and by the operating conditions such as temperature of regulation, flow rate and the rheological parameters of the melt.

A coat hanger die (Figure 1) is commonly used to extrude thermoplastic thin sheets (Puissant et al., 1994; Michaeli and Kaul, 2004; Reifschneider, 2002; Gifford, 2001; Kaymaz, 2005). However, if the melt distribution channel is not designed properly, the velocity at the exit may not be uniform (Chen et al., 1997; Wang, 1991). This leads to a variation in the sheet thickness across the width of the die. Since a tight tolerance on thickness is required for a high-quality plastic sheet, the ultimate goal of this work is to minimise the velocity variations at the die exit.

The design of dies for polymer extrusion is complicated by the non-linear relationship between the resin viscosity, shear rate and temperature dependence; this often involves trial and error corrections to the die geometry to achieve uniform velocities distribution at the exit. Manual correction of the die geometry is a time consuming and costly procedure. The most challenging and demanding work is to find methods of how to reduce or even eliminate die correction. If this is achieved, productivity and cost would be improved and the product will be more competitive. 
Regarding the polymer extrusion process, Winter and Fritz (1986) have used the one-dimensional flow analysis, to design coat-hanger dies, which present a uniform exit velocity distribution; these designs are verified experimentally.

Michaeli and Kaul (2004) have used a combination of finite-element-analysis and flow analysis network with isothermal flow to optimise the die geometry using an evolution strategy algorithm.

Broyden Fletcher Goldfarb Shanno (BFGS) algorithm is commonly used for the resolution of non-linear optimisation problems. We can mention Sun and Gupta (2004) who have optimised a flat die to obtain a homogeneous velocity distribution using BFGS algorithm. A penalty function was introduced to enforce a limit on the maximum allowable pressure drop in the die. Smith et al. (1998a) optimised the coat hanger die to minimise simultaneously the velocity and residence time variations using BFGS algorithm and penalty function.

Smith et al. (1998a) modelled Newtonian and non-Newtonian isothermal flow in a coat hanger die using a generalised Hele-Shaw (HS) approximation, and optimised the die by minimising the pressure drop under the constraint of exit flow uniformity within a pre-set tolerance. The results of the sensitivity analysis needed for the Sequential Quadratic Programming (SQP) algorithm were compared then using direct differentiation and adjoint method. The same author Smith (2003) makes a comparison between two optimisation algorithms with constraint based on SQP and Sequential Linear Programming (SLP) to optimise the geometry for two different materials at various temperatures. The optimisation problem consists in minimising the pressure loss in the die, with an imposed constraint such that a homogeneous velocity distribution within an imposed tolerance is obtained on the outlet side of the die.

All calculation methods (analytical or computational), except the three-dimensional flow model, are unable to simultaneously compute the velocity across the gap of the die land and across the width of the land. However, for complex geometries, the computational resources and time required for the analysis of extrusion dies are considerable. Consequently, the use of evolution strategy algorithm (Michaeli et al., 2001; Sienz et al., 2006) to optimise the extrusion die in three-dimensional analysis is less attractive for designers because of the unacceptable turnaround time for results. The gradient methods (Smith et al., 1998b; Smith, 2003; Sun and Gupta, 2004; Xiaorong et al., 2004; Ettinger et al., 2004; Hua et al., 2004) require the computations of the gradients of the functions, and the computation of gradients by finite difference is time consuming.

The majority of the used optimisation algorithms require a great number of simulations, increasing by this fact the computing time. For the above reasons, in this work we have developed an automatic optimisation algorithm based on a response surface method together with Kriging interpolation and SQP algorithm. This optimisation algorithm is applied to solve two different optimisation problems (optimise the geometrical design and the wall temperature distribution in the coat hanger die). In the first example, the objective function is minimised by varying the geometrical design of the melt distribution channel and in the second example we vary the wall temperature settings. 
We used REM3D ${ }^{\circledR}$ software (Pichelin and Coupez, 1999; Gruau and Coupez, 2005; Silva, 2004) to compute a 3D flow in extrusion dies. This software takes into account strain rate and temperature dependence of the material extruded.

\section{The optimisation benchmark}

In this paper, the coat hanger die is optimised for an Acrylonitrile Butadiene Styrene (ABS, Astalac EPC 10000). The polymer flow is supposed to be purely viscous (the viscoelastic behaviour is not taken into account). This assumption is in agreement with Sun and Gupta (2003) who show that the elongation effect does not influence the exit velocity distribution at the die exit. The constitutive equations used in REM3D ${ }^{\circledR}$ give an expression of the viscosity in function of the shear rate and temperature.

The simulations are performed using a flow rate of $50,000 \mathrm{~mm}^{3} / \mathrm{s}$ with a melt temperature at the die entrance of $240^{\circ} \mathrm{C}$.

The rheological parameters of the ABS are referred in Table 1. A Carreau Yasuda/WLF viscosity model (Balasubrahmanyan and Kazmer, 2003) is used to characterise the temperature and shear rate dependence of viscosity:

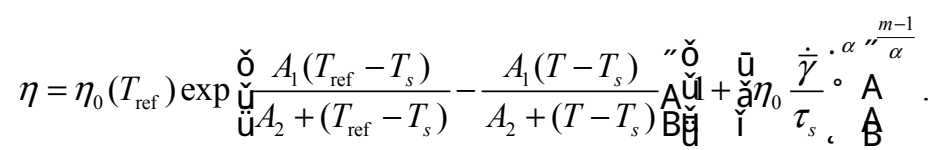

The thermal conductivity $(k)$, density $(\rho)$ and heat capacity $\left(C_{p}\right)$ of the polymer used for the flow simulation were assumed to be constant throughout the range of temperature in the flat die and are referred in Table 2.

Table 1 Parameter of the behaviour laws of Carreau Yasuda, WLF

\begin{tabular}{lccc}
\hline$\eta_{0}$ (Pa.s) & $M$ (no unit) & $\alpha_{0}$ (no unit) & $\tau_{s}(\mathrm{~Pa})$ \\
716.997 & 0.15862 & 1 & 224063 \\
$A_{1}$ (no unit) & $A_{2}(\mathrm{~K})$ & $T_{s}(\mathrm{~K})$ & $T_{\text {ref }}(\mathrm{K})$ \\
20.4 & 101.6 & 397.7 & 524.7 \\
\hline
\end{tabular}

Table 2 Properties of the polymer under study

\begin{tabular}{lc}
\hline Specific heat, $C p\left(\mathrm{~J} / \mathrm{Kg} /{ }^{\circ} \mathrm{K}\right)$ & 1900 \\
Conductivity, $k(\mathrm{~W} / \mathrm{C} / \mathrm{m})$ & 0.115 \\
$\rho\left(\mathrm{Kg} / \mathrm{m}^{3}\right)$ & 969 \\
\hline
\end{tabular}

Owing to the symmetry of the die, only one-half of the passage is modelled as shown in Figure 1. The boundary condition of no slip at the die wall is assumed. Because of the complexity of the geometry and the important aspect ratio, it is necessary to use an anisotropic mesh with elements of minimum size across the thickness of the die, and much larger along the length and width. 
Figure 1 Geometry of the flat die

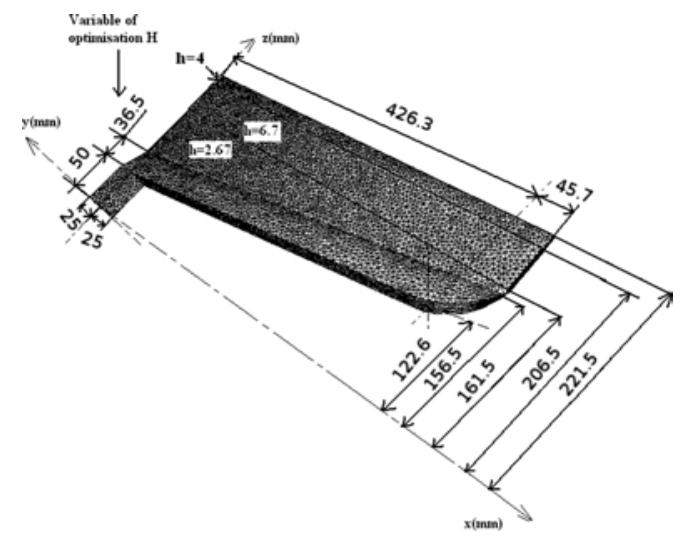

\subsection{Automation of the finite element model}

To save time at the optimisation process and to control efficiently and easily the optimisation strategy, it is necessary to use all the possibilities of automation offered by this code (via Matlab ${ }^{\circledR}$ ). Figure 2 shows a diagram of the principle of operation and

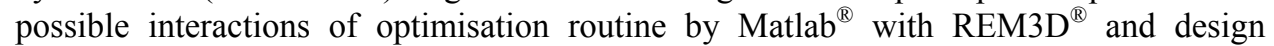
routine. It is also possible to automate all the tasks usually carried out through graphic interface from the creation of FEM until the recovery of the results. In Figure 3 and in the next section, we will see the optimisation procedure that we develop to obtain a good homogenisation of velocity at the die exit.

Figure 2 Optimisation methodology

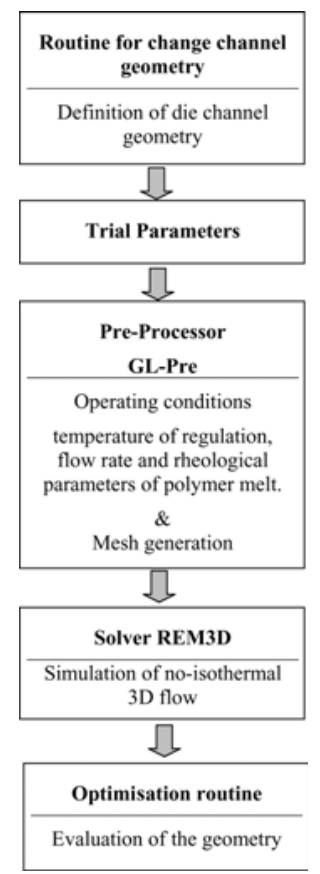


Figure 3 The flowchart of the adopted optimisation strategy

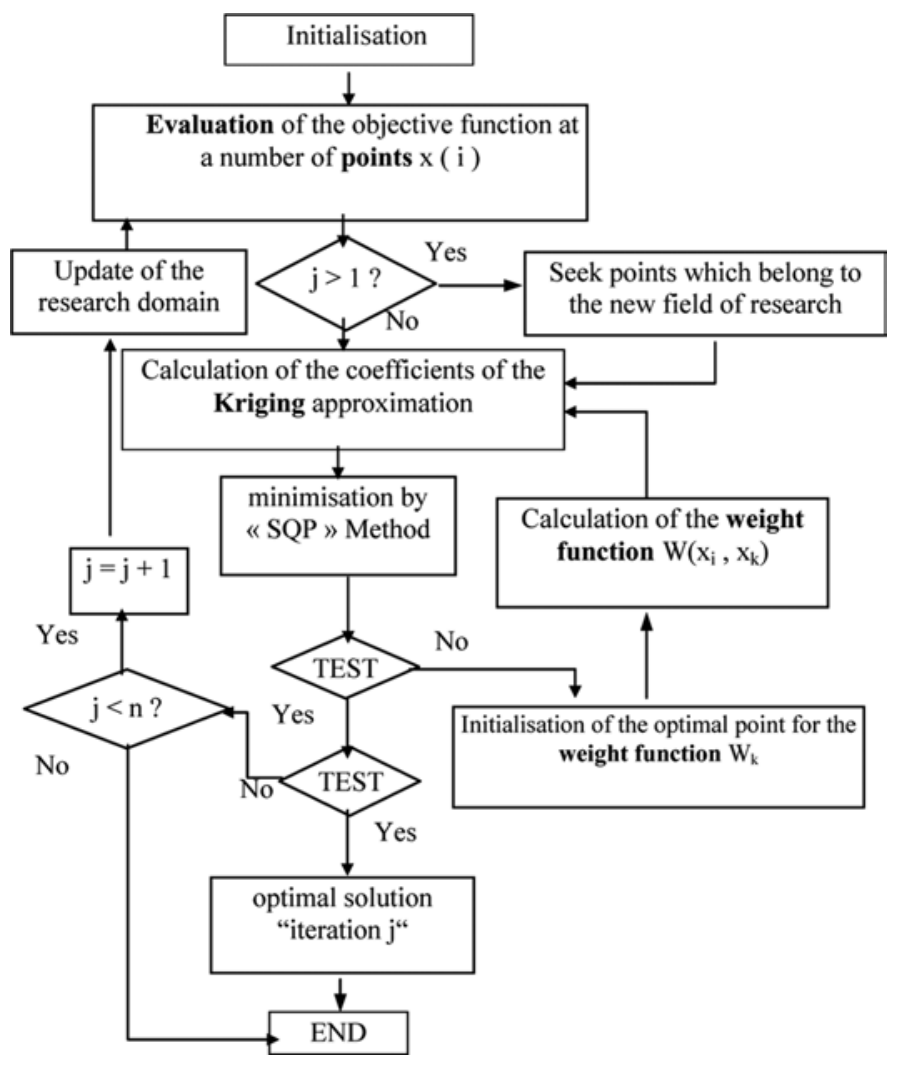

\subsection{Design variables and objective functions}

As a first example, the extrusion die is optimised with the distributor channel height $H$ as a variable. The initial height is fixed at $36.5 \mathrm{~mm}$ and allowed to vary between $30 \mathrm{~mm}$ and $110 \mathrm{~mm}$ during the optimisation process (Figure 1). The wall die temperature is fixed at $230^{\circ} \mathrm{C}$.

As a second example, we optimise the die wall temperature. To this end, die wall temperatures are fixed at three locations. During the optimisation process, the three temperatures can vary between $200^{\circ} \mathrm{C}$ and $280^{\circ} \mathrm{C}$, starting from a uniform temperature of $230^{\circ} \mathrm{C}$. The maximum temperature of $280^{\circ} \mathrm{C}$ is chosen so that there is no polymer degradation.

It was mentioned earlier that the goal in flat die design is to minimise the velocity variation across the die exit. Thus, the objective function is defined as follows:

$$
J=\frac{1}{N} \bigoplus_{i=1}^{N} \underset{\mathrm{u}}{\mathrm{a}} \frac{v_{i}-\left.\bar{v}\right|^{\cdot 2}}{\bar{v}}
$$

where $N$ is the total number of nodes at the die exit in the middle plane, $v_{i}$ is the velocity at the mid-plan of the gap (i.e., maximum velocity of the Poiseuille profile calculated by the finite element programme) and $\bar{v}$ is the average exit velocity. 


\subsection{Optimisation procedure}

The response surface method (Myers and Montgomery, 2002; Lebaal et al., 2005) consists in the construction of an approximate expression of the objective function starting from a limited number of evaluations of the real function. To obtain a good approximation, we used a Kriging interpolation described in the next section. In this method, the approximation is computed by using the evaluation points by Composite Design of Experiments (CDEs) (Montgomery, 2005). After the interpolation of the objective function, we minimise it using an SQP method (see Figure 3). In addition, to avoid local minima, a successive minimisation is carried out by changing the initial points of the SQP algorithm starting from each point of the DOE. The best solution among those obtained in various iterations is then considered. After we have obtained the best minimum, a weight function of Gaussian type is used to slightly vary the approximate problem and make the response surface more accurate locally. The iterative procedure stops when the successive points are superposed with a tolerance $\varepsilon=10^{-3}$.

In the first example (geometrical optimisation), with one geometric variable, we use five evaluation points to obtain a good interpolation.

In the second example (die wall temperature optimisation), with three variables, we use 35 evaluation points to have a good interpolation.

\subsection{Kriging interpolation}

Kriging was introduced to meet the needs for minerals prospection. It was used to reconstitute the position of an ore seam starting from concentrations obtained by drilling. We limit ourselves to present the Kriging as an interpolation technique (Kaymaz, 2005; Li et al., 2004), which allows to model very efficiently complex surfaces of arbitrary shapes. It is applied here to represent the objective and constraint functions in an explicit form, according to the optimisation variables. The construction of a Kriging model can be explained as follows:

$$
\tilde{J}(x)=p^{T}(x) a+Z(x)
$$

with $p(x)=\left[p_{1}(x), \ldots, p_{m}(x)\right]^{T}$, where $m$ denotes the number of the basis function in regression model, $a=\left[a_{1}, \ldots, a_{m}\right]^{T}$, is the coefficient vector, $x$ is the design variables, $\tilde{J}(x)$ is the unknown objective or constraint interpolation function and $Z(x)$ is the random fluctuation. The term $p^{T}(x) a$ in equation (3) indicates a global model of the design space, which is similar to the polynomial model in a Moving Least Squares (MLS) approximation. The second part in equation (3) is a correction of the global model. It is used to model the deviation from $p^{T}(x) a$ so that the whole model interpolates response data from the function.

The output responses from the function are given as follows:

$$
F(x)=\left\{f_{1}(x), f_{2}(x), \ldots, f_{n}(x)\right\} .
$$

From these outputs, the unknown parameters $a$ can be estimated:

$$
a=\left(P^{T} R^{-1} P\right)^{-1} P^{T} R^{-1} F
$$


where $P$ is a vector including the value of $p(x)$ evaluated at each of the design variables and $R$ is the correlation matrix, which is composed of the correlation function evaluated at each possible combination of the points of design:

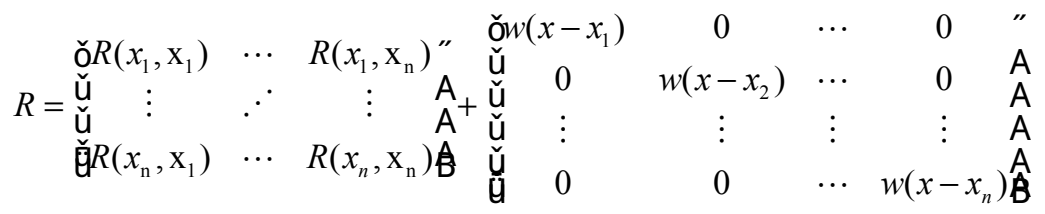

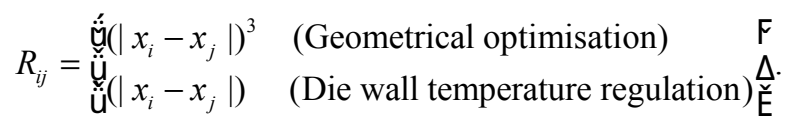

A weight function of Gaussian type with a circular support is adopted for the Kriging interpolation because its derivatives with respect to the coordinates exist to any desired order. It takes the following relationship:

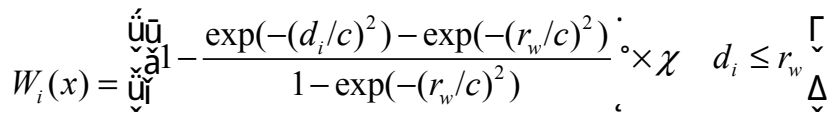

$$
\begin{aligned}
& \text { ù } \chi \quad d_{i} \geq r_{w} \mathrm{E}
\end{aligned}
$$

where $d_{i}=\sqrt{€_{J=1}^{n}\left(x^{J}-x_{i}^{J}\right)^{2}}$ is the distance from a discrete node $x_{i}$ to a sampling point $x$ in the domain of support with radius $r_{w}$, and $c$ is the dilation parameter. $c=r_{w} / 4$ is used in computation. $0 \leq x \leq 1$ represents the degree of the importance of the weight function.

The second part in equation (3) is in fact an interpolation of the residuals of the regression model $p^{\mathrm{T}}(x) a$. Thus, all response data will be exactly predicted and are given as follows:

$$
Z(x)=r^{T}(x) \beta
$$

where $r^{T}(x)=\left\{R\left(x, x_{1}\right), \ldots, R\left(x, x_{n}\right)\right\}$

The parameters $\beta$ are defined as follows:

$$
\beta=R^{-1}(F-P a) .
$$

\section{Results and discussion}

\subsection{Geometrical optimisation}

The objective of this technique is to reach the global minimum on the field domain. The optimisation consists in adjusting the height of the melt distribution channel $(H)$ (see Figure 1) to minimise the velocity variation at die exit.

The optimisation algorithm, described in the previous section, is used to optimise a flat die for ABS. The flat die based on geometric parameters shown in Figure 1 was employed as the initial design for the optimisation scheme.

A representative convergence history during an optimisation run is represented in Figure 4. In this case, the initial value of the melt distribution channel depth (variable $H$ ) 
is $36.5 \mathrm{~mm}$. After two iterations, the superposition of the successive points fell below the cutoff of $\varepsilon=10^{-3}$ and the simulation stopped. This optimisation run represents $11 \mathrm{~h}$ $23 \mathrm{~mm}$ of CPU time on a computer Pentium IV, $3 \mathrm{GHz}, 1$ Go RAM. Under the constraints of die geometry, melt flow rheology and operating conditions, the optimal value of the melt distribution channel depth was found at $H=94.9 \mathrm{~mm}$.

Figure 4 Fast convergence of the objective function 'design optimisation'

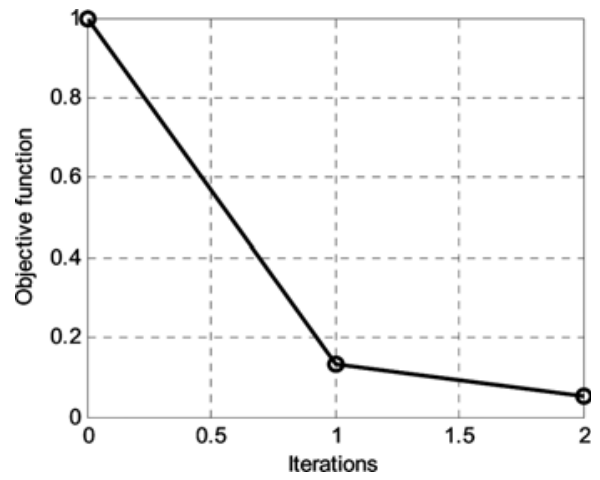

The same figure illustrates the evolution of the normalised objective function according to the number of iteration. We can see that it is varying quite fast at the beginning of the optimisation until the second step. Its final value is about $5.3 \times 10^{-2}$, which represents a total variation of about $94.7 \%$.

Qualitatively, velocity distributions at the exit of the optimised die (Figure 5(B)) are more uniform than the exit velocity in the initial die design (Figure 5(A)). It is obvious from Figure 5(A) that in the initial die design the exit velocity at the border of the die is significantly higher than at the centre of the die. After the optimisation, we observe in Figure 6 that the exit velocity distributions at the mid-plane in the gap for the optimised die design is much more uniform across the entire width of the half die. The exit velocity drops to zero in the small regions near the border of this die to satisfy the no slip condition at the walls.

Figure 5 (A) Velocity distributions of the initial and (B) optimised designs of the flat die (see online version for colours)

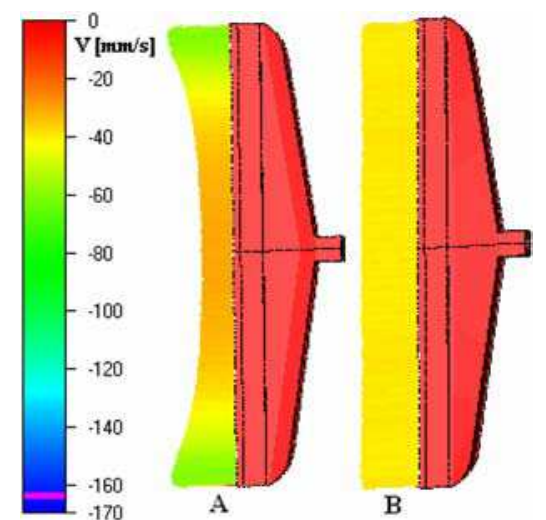


Figure 6 Exit velocity across the width of the mid-flat dies (see online version for colours)

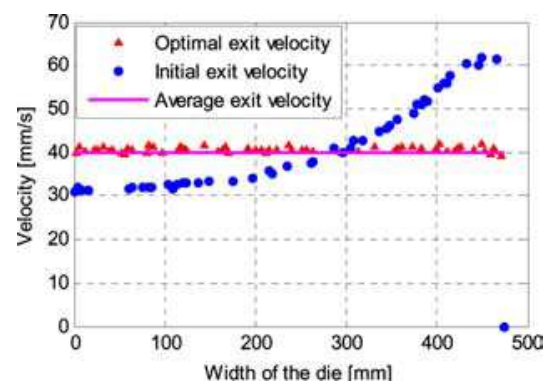

The pressure drop in the initial die design is $4.423 \mathrm{MPa}$ (Figure 7(A)). It should be noted that the pressure drop decreases during the optimisation iteration. The total pressure drop in the optimised die was decreased by $49.9 \%$ or $2.215 \mathrm{MPa}$ (Figure 7(B)). Compared with the initial geometry, the flow rate can be increased by $140 \%$ at the same pressure drop (Figure 8).

Figure 7 (A) Pressure distributions in initial and (B) optimised designs of the flat die (see online version for colours)

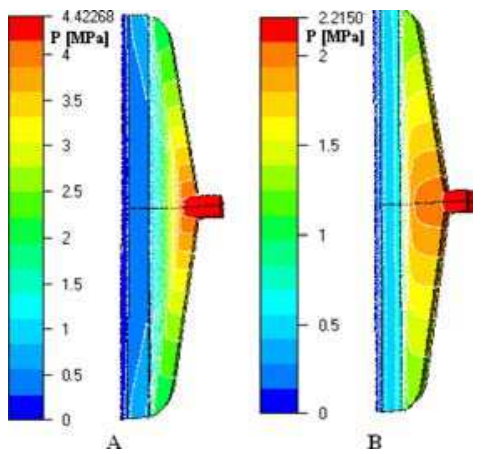

Figure 8 (A) Velocity and (B) pressure distributions in optimised die designs with increase the flow rate of $140 \%$ (see online version for colours)

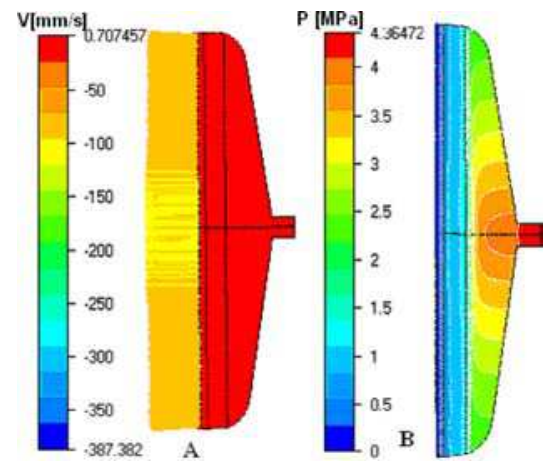

Non-uniform exit temperature distribution is observed in the initial die (Figure 9(A)). However, it is to be noted that more polymer is flowing towards the edge because of the shear heating. Hence, the temperature is lower near the middle of the die and 
higher near the edge. By comparison, the shear heating in the optimal die and the temperature distribution are more uniform (Figure 9(B)) because of the homogeneous distribution of the exit velocity.

Figure 9 (A) Temperature distributions in the mid-plane of the initial and (B) optimised flat die (see online version for colours)

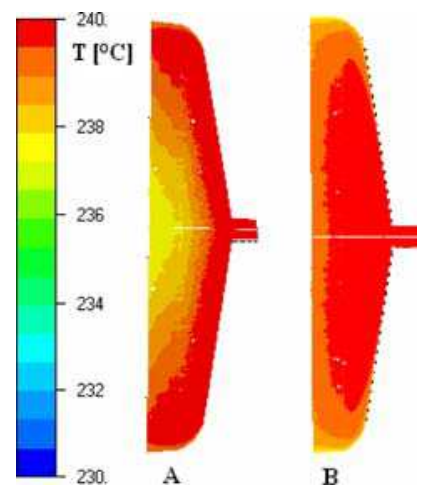

\subsection{Optimisation of the die wall temperature}

The convergence history during an optimisation run is represented (Figure 10). After three iterations, the simulation stopped. This optimisation run represents Five days and $9 \mathrm{~h}$ of CPU time in a computer Pentium IV, $3 \mathrm{GHz}, 1$ Go RAM. We notice that the normalised objective function is varying quite fast at the beginning of the optimisation until the third step. Its final value is about $6.88 \times 10^{-2}$. The initial values of the die wall temperatures are $T_{1}=T_{2}=T_{3}=230^{\circ} \mathrm{C}$, where $T_{1}$ represents the temperature in the centre of die, $T_{3}$ the temperature near the border of the die and $T_{2}$ the temperature between $T_{1}$ and $T_{3}$ (Figure 11).

To improve the uniformity of velocity at the die exit, the optimal values for the temperatures profile of the die wall in the three zones are varied from $T_{\mathrm{in}}=230^{\circ} \mathrm{C}$ to $T_{1}=276.4^{\circ} \mathrm{C}, T_{2}=257.02^{\circ} \mathrm{C}$ and $T_{3}=223.88^{\circ} \mathrm{C}$ (Figure 12), respectively, in zones one, two and three.

Figure 10 Fast convergence of the objective function 'regulation of temperature'

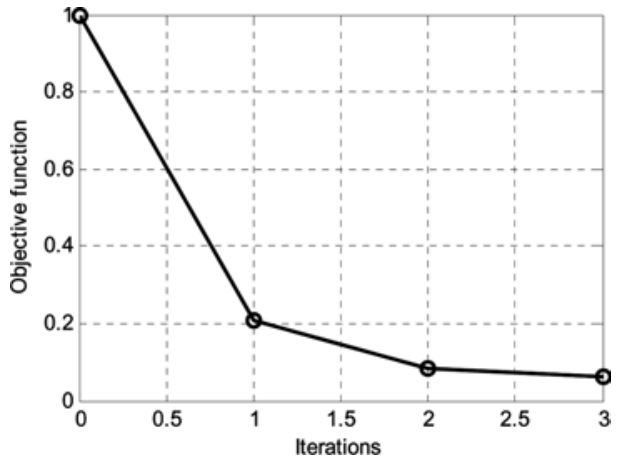


Figure 11 Distribution of three variables of temperature in the optimised die temperature distribution (see online version for colours)

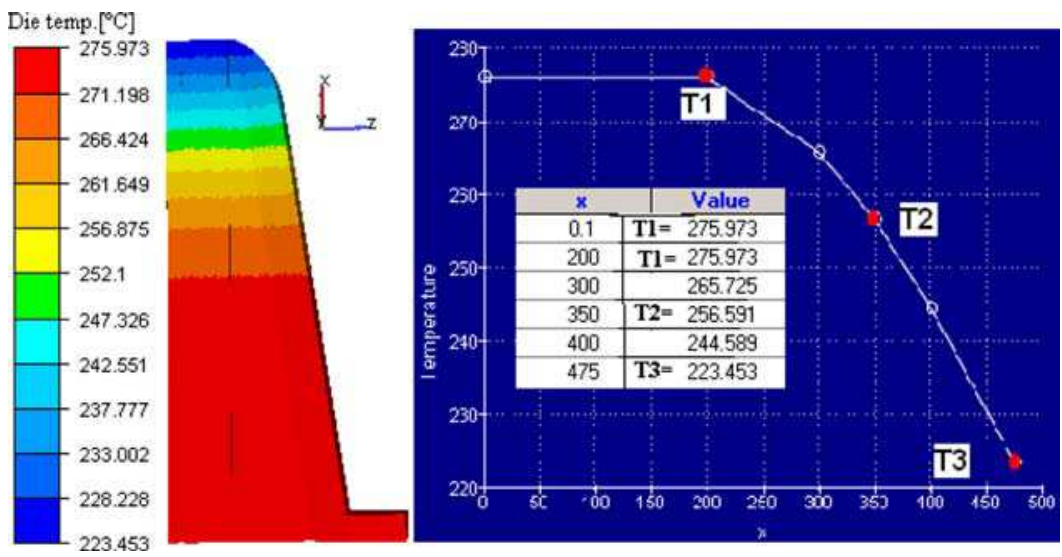

Figure 12 Evolution of three variables of temperature of regulation during the process of optimisation (see online version for colours)

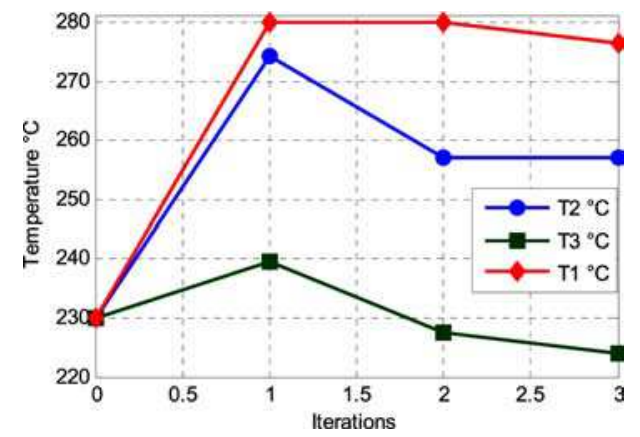

We find that the temperature of the initial regulation (Figure 13(A)) gives a non-uniform exit velocity distribution. This velocity distribution in the initial die is obtained with a uniform die wall temperature $T=230^{\circ} \mathrm{C}$. We notice in Figure 14, that in the centre of the die, the velocities are lower; on the other hand, in the two parts close to the end of the die we observe that the velocities increase until $50 \%$. The optimal solution shows higher wall temperatures in the centre of the die. On the other hand, the temperatures are lower on the edge to increase the viscosity of polymer, which generates a reduction in the flow towards the edge. With these optimal temperatures of regulation, we could obtain a balance, which provides homogeneous exit velocities distribution according to all the width of the die (Figures 13(B) and 14).

For the initial temperature of regulation, the pressure drop is about $4.42 \mathrm{MPa}$ (Figure 15(A)). It should be noted that the pressure drop decreases during the optimisation iteration. The total pressure drop in the die for the optimal temperature of regulation was decreased by $26.88 \%$, which represents $3.23 \mathrm{MPa}$ (Figure $15(\mathrm{~B})$ ).

We note a higher exit temperature for the optimal regulation profile because the wall temperature has increased in the centre of the die by $46^{\circ} \mathrm{C}$ and $27^{\circ} \mathrm{C}$, respectively, in $T_{1}$ and $\mathrm{T}_{2}$. In the small regions near the border of this die, the temperature decreases by only $7^{\circ} \mathrm{C}\left(\mathrm{T}_{3}\right)$ (Figure 12$)$. 
Figure 13 (A) Velocity distributions of the initial and (B) optimised die temperature distribution (see online version for colours)

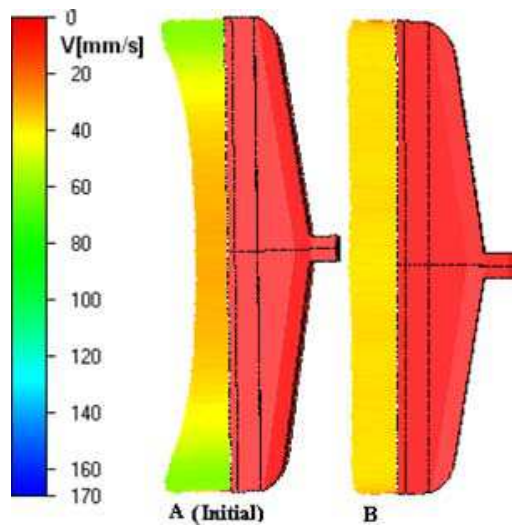

Figure 14 Exit velocity across the width of the flat dies in the initial and optimised die wall temperature distribution (see online version for colours)

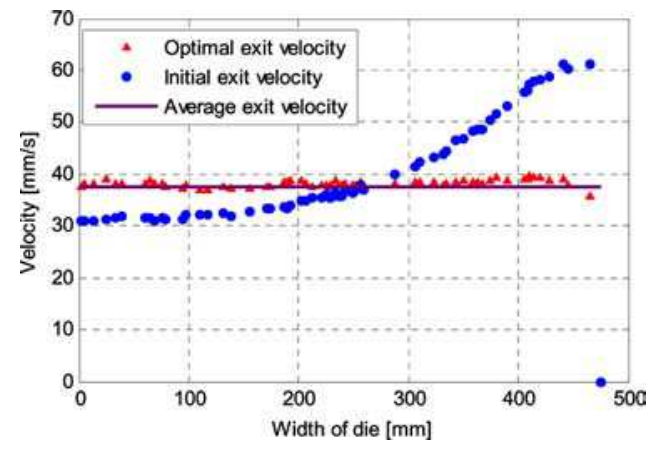

Figure 15 (A) Pressure distributions in initial and (B) optimised die wall temperature distribution (see online version for colours)

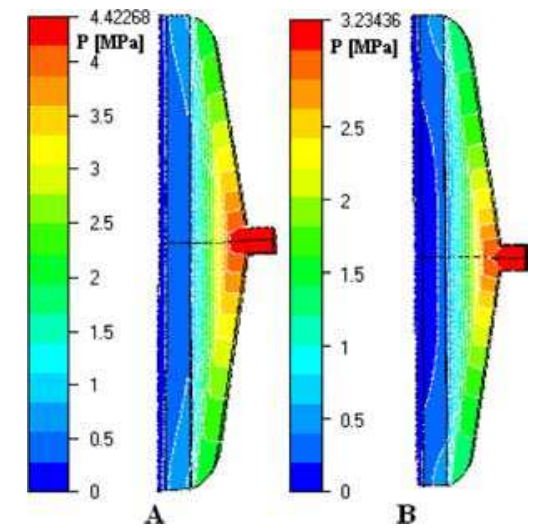

Figure 16 illustrates the melt temperature distributions in the mid-plane of the initial (A), and optimised (B) die wall temperature regulation. 
Figure 16 (A) Temperature distributions in the mid-plane of the initial and (B) optimised die wall temperature distribution (see online version for colours)

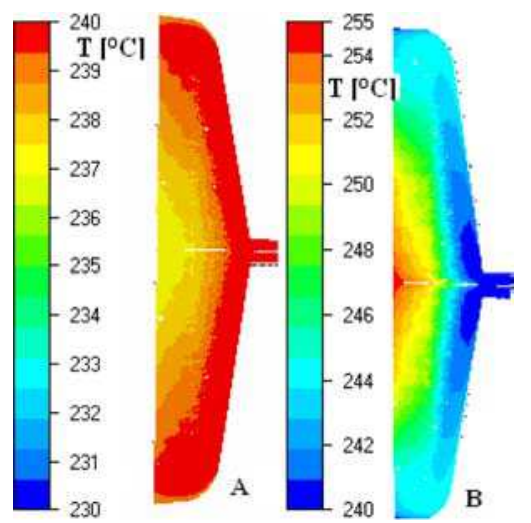

We note a difference in melt temperature along the die width for the optimal die temperature regulation (Figure 16(B)). But, the great difference of regulation temperature (about $50^{\circ} \mathrm{C}$ ) on the wall die leads to a variation of melt temperature of only $10^{\circ} \mathrm{C}$ across the die exit width. This variation could, however, generate difficulties during drawing and cooling of the sheet obtained on the outlet side of the die.

\section{Conclusion and prospects}

We have obtained good optimisation results using a response surface method with a very fast convergence (two iterations). This is due to the good interpolation obtained using Kriging interpolation. The weight function and the various evaluations of the interpolation function (requiring only small CPU time) allow to determine an accurate global minimum.

An optimisation methodology for the die design for polymer sheet extrusion has been developed. This optimisation methodology may be applicable to optimise both operating conditions (in our case the die wall temperature) or the geometrical design.

To save time and control easily the optimisation procedure, we have linked this programme with REM3D ${ }^{\circledR}$ software and a separate design routine. The optimisation programme uses the REM $3 \mathrm{D}^{\circledR}$ software to simulate the polymeric flow in the flat die.

This programme successfully optimised in the first approach the geometrical design of a flat die for a uniform velocity and temperature distribution at the die exit and decreasing in the same time the pressure drop in the die.

In the second approach, to preserve the existing geometry and avoid to design and manufacture a new die, the wall temperature distribution is optimised in heterogeneous way (i.e., the wall temperatures are different in the various zones of the die). This same approach permits to optimise the velocity distribution in the existing die.

For our future work, we plan to optimise more complex geometries of extrusion die for various polymers and for multiple operating conditions. 


\section{References}

Balasubrahmanyan, G. and Kazmer, D. (2003) 'Thermal control of melt flow in cylindrical geometries', SPE Annual Technical Conference, 4-8 May, Nashville, TN, USA, pp.387-391.

Chen, C., Jen, P. and Lai, F.S. (1997) 'Optimization of the coat hanger manifold via computer simulation and orthogonal array method', Polymer Engineering and Science, Vol. 37, No. 1, pp.188-196.

Ettinger, H.J., Sienz, J., Pittman, J.F.T. and Polynkin, A. (2004) 'Parameterization and optimisation strategies for the automated design of u PVC profile extrusion dies', Structural and Multidisciplinary Optimization, Vol. 28, pp.180-194.

Gifford, W.A. (2001) 'The effect of wall slip on the performance of flat extrusion dies', Polymer Engineering and Science, Vol. 41, pp.1886-1892.

Gruau, C. and Coupez, T. (2005) '3D tetrahedral, unstructured and anisotropic mesh generation with adaptation to natural and multidomain metric', Computer Methods in Applied Mechanics and Engineering, Vol. 194, pp.4951-4976.

Hua, Li., Wang, Q.X. and Lam, K.Y. (2004) 'Development of a novel meshless local Kriging (LoKriging) method for structural dynamic analysis', Computer Methods in Applied Mechanics and Engineering, Vol. 193, pp.2599-2619.

Kaymaz, I. (2005) 'Application of Kriging method to structural reliability problems', Structural Safety, Vol. 27, pp.133-151.

Lebaal, N., Puissant, S. and Schmidt, F. (2005) 'Rheological parameters identification using in situ experimental data of a flat die extrusion', Journal of Materials Processing Technology, Vols. 164-165, pp.1524-1529.

Michaeli, W. and Kaul, S. (2004) 'Approach of automatic extrusion die optimisation', Journal of Polymer Engineering, Vol. 24, pp.123-136.

Michaeli, W., Kaul, S. and Wolff, T. (2001). 'Computer aided optimisation of extrusion dies', Journal of Polymer Engineering, Vol. 21, pp.225-237.

Montgomery, D.C. (2005) Design and Analysis of Experiments, John Wiley and Sons, Inc., USA.

Myers, R.H. and Montgomery, D.C. (2002) Response Surface Methodology, Process and Product Optimization Using Designed Experiments, 2nd ed., Wiley Interscience Publication, USA.

Pichelin, E. and Coupez, T. (1999) 'A Taylor discontinuous Galerkin method for the thermal solution in 3D mold filling', Computer Methods in Applied Mechanics and Engineering, Vol. 178, pp.153-169.

Puissant, S., Demay, Y., Vergnes, B. and Agassant, J.F. (1994) 'Two-dimensional multilayer coextrusion flow in a flat coat-hanger die. Part I: modelling', Polymer Engineering and Science, Vol. 34, pp.201-208.

Reifschneider, L.G. (2002) 'Automated sheet die design', SPE Annual Technical Conference, 5-9 May, San Francisco, CA, USA.

Sienz, J., Bates, S.J. and Pittman, J.F.T. (2006) 'Flow restrictor design for extrusion slit dies for a range of materials: simulation and comparison of optimization techniques', Finite Elements in Analysis and Design, Vol. 42, pp.430-453.

Silva, L. (2004) Viscoelastic Compressible Flow and Applications in 3D Injection Molding Simulation, Thèse de Doctorat, CEMEF.

Smith, D.E. (2003) 'An optimisation-based approach to compute sheeting die designs for multiple operating conditions', SPE Annual Technical Conference, 4-8 May, Nashville, TN, USA, pp.315-319.

Smith, D.E., Tortorelli, D.A. and Tucker, C.L. (1998a) 'Optimal design for polymer extrusion. Part I: sensitivity analysis for non-linear steady-state systems', Computer Methods in Applied Mechanics and Engineering, Vol. 167, pp.283-302.

Smith, D.E., Tortorelli, D.A. and Tucker, C.L. (1998b) 'Optimal design for polymer extrusion. Part II: sensitivity analysis for weakly-coupled non-linear steady state systems', Computer Methods in Applied Mechanics and Engineering, Vol. 167, pp.303-323. 
Sun, Y. and Gupta, M. (2003) 'Effect of elongational viscosity on the flow in flat die', International Polymer Processing, Vol. 18, pp.356-361.

Sun, Y. and Gupta, M. (2004) 'Optimization of a flat die geometry', SPE Annual Technical Conference, 16-20 May, Chicago, IL, USA, Vol. 3, pp.3307-3311.

Wang, Y. (1991) 'The flow distribution of molten polymers in slit dies and coat hanger die through three-dimensional finite element analysis', Polymer Engineering and Science, Vol. 31, pp.204-212.

Winter, H.H. and Fritz, H.G. (1986) 'Design of dies fort the extrusion of sheets and annular parisons: the distribution problem', Polymer Engineering and Science, Vol. 26, pp.543-553.

Xiaorong, Y., Changyu, S., Chuntai, L. and Lixia, W. (2004) 'Optimal design for polymer sheeting dies', Chinese Journal of Computational Mechanics, Vol. 21, pp.253-256. 